\title{
Turismo, empleo y desarrollo
}

\author{
Manuel Ángel Santana Turégano \\ Universidad de La Laguna. Departamento de Sociología \\ masantur@ull.es
}

\section{Resumen}

El artículo analiza los factores que determinan la «calidad» del empleo turístico a partir del estudio del caso de Maspalomas (Canarias). Los resultados de la investigación señalan que las condiciones de empleo en turismo vienen determinadas por: 1) la posición de un destino en la red internacional de elaboración de servicios turísticos; 2) la estabilidad de la demanda; 3) los factores institucionales; y 4) la medida en que el desarrollo turístico es endógeno. Además, el estudio lleva a plantear que el empleo no debería ser el único factor a la hora de evaluar la «bondad» de un modelo de desarrollo turístico, sino que también debería considerarse el reparto de los beneficios de la actividad en forma de rentas empresariales.

Palabras clave: turismo, empleo, red de empresas, rentas, Islas Canarias.

\section{Abstract. Tourism, employment and development}

This article looks at the factors determining the quality of tourism employment, through the case study of Maspalomas (Canary Islands). The study shows that labour conditions in tourism depends upon: 1 ) the position of a touristic destination in the international network of enterprises that manufacture touristic services; 2 ) the stability of touristic demand; 3) the institutional factors; 4) the extent in which tourism is self-sustained. Furthermore, the study suggests that employment should not be the only factor considered when evaluating the "goodliness" of a model of touristic development. The distribution of tourism benefits through enterprises profits should also be taken into account.

Key words: tourism, employment, net of enterprises, benefits, Canary Islands.

\section{Sumario}

Introducción

1. Metodología

2. Organización de la oferta turística

en Maspalomas

3. Factores que inciden en la calidad del empleo turístico
4. Redes sociales y origen geográfico de los empleados

5. Conclusiones

6. Agradecimientos

Bibliografía 


\section{Introducción}

Tras la aparición del turismo de masas a mitad del siglo XX ha surgido una intensa polémica acerca del turismo como factor de desarrollo. El debate ha llegado a alcanzar tal importancia que hay autores que plantean que las teorías sociológicas sobre el turismo se han vertebrado en torno a la disyuntiva sobre si el turismo es un factor de desarrollo de la sociedad receptora o, por el contrario, un reflejo del subdesarrollo (Rubio Gil 2003: 270). Hasta la década de los setenta, la mayoría de los estudios, desde una perspectiva optimista, concebían al turismo como una especie de "pasaporte para el desarrollo", ya que siendo el mayor contribuyente al crecimiento económico, se pensaba que la actividad permitiría la modernización de la actividad económica y de la sociedad receptora (Rubio Gil 2003: 273; Santana Talavera 1997: 70; Sinclair 1991: 17; Mathieson y Wall 1990). Como contestación a estos planteamientos surgió una literatura crítica que ponía el énfasis en los aspectos más negativos del turismo, que llegó a ser visto como una forma de neocolonialismo (Turner y Ash 1991 ${ }^{1}$; Gaviria 1978). En cualquier caso, existe consenso en torno a la idea de que el desarrollo turístico crea empleo (Santana Talavera 1997). En la actualidad, la contribución del turismo a la creación de empleo y al crecimiento del PIB son vistos como los principales mecanismos mediante los cuales la actividad contribuye al bienestar de las comunidades en que se desarrolla (Wanhill 2000: 133). Como consecuencia de todo ello, la generación de puestos de trabajo es casi siempre la variable más considerada a la hora de evaluar el desarrollo turístico. La difusión de esta idea ha llegado hasta el punto en que no pocos estudios, dando esto por establecido, se han concentrado en estimar el número de empleos directos o indirectos que genera el desarrollo turístico o las diferentes tasas de creación de empleo que tendrían los distintos modelos turísticos. En este sentido, distintas aportaciones establecen que un «modelo turístico hotelero" genera más empleos, por unidad de medida plazas turísticas, que otros modelos turísticos (para una revisión de estas aportaciones, véase Santana Talavera 1997: 74-75).

Sin embargo, este enfoque cuantitativo hace que se tenga en cuenta tan sólo el número de empleos creados y no la «calidad» de los mismos. Así, algunas de las críticas que desde los enfoques que podríamos denominar pesimistas se realizan al desarrollo turístico se fundamentan en la constatación de que muchos de los empleos creados por el turismo en las localidades en que se asienta son de «baja calidad» (mal remunerados, inestables y poco cualificados) y los pocos empleos de calidad que se generan son ocupados en la mayoría de los casos por población ajena a las localidades en que se da el desarrollo turístico. Según Bayón García (1997), el 75\% de los trabajadores del sector en España se encuentran en una situación jurídica precaria, y las condiciones laborales del sector, marcadas por la temporalidad, las largas jorna-

1. La edición original inglesa es de 1976. Para una visión sintética de esta literatura puede verse Rubio Gil (2003: 274-275) y Santana Talavera (1997: 78-79). 
das laborales y las remuneraciones relativamente bajas, situarían al sector, comparativamente, por debajo de otros sectores (Brunet Icart y Belzunegui Eraso 2003: 177). Sin embargo, no hay por qué pensar que la «baja calidad» de los empleos creados sea necesariamente debida a características intrínsecas al sector turístico. La manera en que se organiza desde las empresas la provisión de los servicios que demandan los turistas y el reclutamiento de la mano de obra que se necesita para llevarla a cabo puede determinar la "calidad» del empleo en mayor medida que las características intrínsecas del sector turístico. En distintos sectores económicos puede organizarse la producción de formas distintas, y de cómo esto se haga va a depender en gran medida la "calidad» del empleo resultante. Así, la posible dependencia que implicaría el turismo no sería una consecuencia derivada de características intrínsecas al turismo sino de cómo éste se organiza. Otro punto débil que presentan las líneas tradicionales de trabajo respecto a la relación entre el turismo y el desarrollo socioeconómico es que al centrarse tan sólo en el empleo olvidan una de las principales vías mediante las cuales la aparición de una nueva actividad económica puede repercutir en el desarrollo socioeconómico de una comunidad, la generación de rentas. A lo largo del siglo XX, en la mayor parte de las sociedades capitalistas occidentales los beneficios de las distintas actividades económicas se han repartido entre las rentas del trabajo (salarios) y las rentas del capital (beneficios empresariales). El que el debate se haya centrado tan sólo en una de las porciones en que se divide la riqueza generada por la actividad turística ha sustraído a la discusión la cuestión verdaderamente crucial: cómo se reparte socialmente la riqueza generada por una actividad económica. Especialmente en el turismo resulta pertinente plantearse el reparto social de la riqueza generada por una actividad económica, pues muchos de los «capitales» a partir de los cuales se construye la actividad turística son «intangibles» sobre los cuales nadie puede presentar títulos de propiedad. ${ }^{2}$ El trabajo que aquí se presenta pretende cumplir dos objetivos. En primer lugar, tratará de analizar los factores que influyen en la calidad del empleo generado por el desarrollo turístico. En segundo lugar, se planteará que es necesario relacionar la composición del capital con las características del empleo, ya que existen elementos para pensar que existe relación entre la distribución y el origen del capital que pone en marcha la actividad turística en una localidad y las características del empleo en la misma.

2. Dado que los aspectos que finalmente atraen a los turistas a un destino concreto son bienes colectivos de los cuales toda una comunidad es propietaria (cuestiones como la calidad paisajística, la calidad ambiental de las playas y espacios naturales, la seguridad ciudadana, la tranquilidad o su opuesto, el «ambiente»), resulta cuando menos una cuestión a debatir que en el reparto social de la riqueza generada por la actividad turística las comunidades locales sólo se beneficien a través del empleo. 


\section{Metodología}

La estrategia utilizada para analizar los factores que influyen en la calidad del empleo generado por el desarrollo turístico es la del estudio de casos, concretamente el de Maspalomas. La elección de la estrategia obedece a la utilidad que ha demostrado para avanzar en el conocimiento de cuestiones relativas a la organización de la producción y las condiciones de empleo. Siguiendo las ideas planteadas por Castillo (1989) y Osterman (1988), el estudio de casos no agota su sentido en la descripción/ explicación detallada de una realidad concreta, sino que en su comparación con otros casos permite realizar generalizaciones fundamentadas empíricamente, y otros autores, lo que permite huir de las "generalizaciones con escasa (o ninguna) base empírica que manifiestan, muchas veces, más las imágenes y quizá la buena voluntad [...] cuando no el desconocimiento que todavía se tiene de la realidad» (Castillo 1989: 19-20). Con 97.596 plazas turísticas alojativas en el año 2002 en un solo municipio, Maspalomas, localidad situada en el sur de Gran Canaria, constituye la mayor concentración turística de Canarias, de España y una de las mayores del mundo. Unos 2,5 millones ${ }^{3}$ de turistas visitan anualmente la localidad, produciendo cerca de 25 millones de pernoctaciones. ${ }^{4}$

3. Según las estadísticas oficiales del Gobierno de Canarias (2003), las 97.956 plazas alojativas del municipio de San Bartolomé de Tirajana (lo que se conoce turísticamente como «Maspalomas») representaban en 2002 el 70,91\% de las 138.134 plazas de Gran Canaria. La cifra de turistas en Gran Canaria para ese año podían estimarse en 3.306.948 turistas. Esta cifra se obtendría de sumar a 2.886.791 turistas extranjeros que visitaron Gran Canaria en 2002, según datos recogidos por AENA y facilitados por Gobierno de Canarias 2003, los 420.157 españoles alojados en establecimientos hoteleros, según los datos facilitados por la misma fuente. Esto daría un total de 3.306.948, a los que habría que sumar los españoles alojados en establecimientos extrahoteleros. $\mathrm{Si}$, en función del reparto de las plazas turísticas en la isla de Gran Canaria, estimamos que Maspalomas concentra el 70,91\% de la actividad en la isla, y multiplicamos el total de turistas por esa cantidad, obtendríamos la cifra de 2.344.956,83 turistas, a los que habría que añadir los españoles alojados en establecimientos extrahoteleros. Por tanto, creemos que la estimación total de cerca de 2,5 millones de turistas para la localidad en el año 2002 es bastante cercana a la realidad. Lamentablemente no podemos facilitar la cifra exacta porque las estadísticas del turismo en Canarias y en España no son todo lo exactas que desearíamos, pero pensamos que en cualquier caso esta cifra es bastante aproximada.

4. La estimación de que Maspalomas concentra en torno a unos 25 millones de pernoctaciones se ha realizado a partir del total de 57.919.228 pernoctaciones en el total de la provincia de Las Palmas. Dado que los modelos turísticos de las tres islas (Gran Canaria, Fuerteventura y Lanzarote) que componen la provincia son similares, se ha considerado que el reparto de las pernoctaciones por islas puede considerarse proporcional al de los turistas. Como Gran Canaria concentra al 48\% de turistas que recibe la provincia (Gobierno de Canarias 2003), se ha estimado que concentra un $48 \%$ del total de pernoctaciones turísticas de la provincia, aproximadamente 28.276.429 pernoctaciones para el año 2000, algo más de un 8\% del total de España. San Bartolomé de Tirajana concentra el 72\% de las plazas turísticas de Gran Canaria, por lo que puede estimarse en 21.207.322 las pernoctaciones que tuvieron lugar en el año 2000, es decir, el 6,1\% del total de pernoctaciones turísticas que se realizaron en España ese año. Habría otra manera de realizar esta estimación: el INE (2001: 33) estimaba que sólo en los establecimientos hoteleros de San Bartolomé de 
Tabla 1. La actividad turística en Maspalomas, Gran Canaria y Canarias, 2002.

\begin{tabular}{llll}
\hline & Plazas turísticas & Turistas extranjeros & Pernoctaciones \\
\hline Canarias & 381.537 & 9.778 .503 & 84.386 .507 \\
Gran Canaria & 138.134 & 2.886 .791 & 28.276 .429 (est.) \\
Maspalomas & 97.956 & 2.500 .000 (est.) & 25.000 .000 (est.) \\
\hline
\end{tabular}

Fuente: elaboración propia con datos de Gobierno de Canarias 2003, INE 2002a, 2002b y 2002c.

Tabla 2. La actividad turística en España, 2002. Pernoctaciones por CCAA.

\begin{tabular}{|c|c|c|c|c|c|c|c|c|}
\hline & \multicolumn{2}{|c|}{ Apartamentos } & \multicolumn{2}{|l|}{ Hoteles } & \multicolumn{2}{|l|}{ Cámpings } & \multicolumn{2}{|l|}{ Total turismo } \\
\hline & Pernoctac. & $\%$ & Pernoctac. & $\%$ & Pernoctac. & $\%$ & Pernoctac. & \% España \\
\hline Andalucía & 5.508 .198 & 6,77 & 35.326 .510 & 15,86 & 3.821 .775 & 12,26 & 44.656 .483 & 13,32 \\
\hline Baleares & 11.576 .035 & 14,23 & 47.481 .998 & 21,32 & 136.327 & 0,44 & 59.194 .360 & 17,66 \\
\hline Canarias & 47.497 .256 & 58,38 & 36.791 .317 & 16,52 & 97.934 & 0,31 & 84.386 .507 & 25,17 \\
\hline Cataluña & 6.004 .378 & 7,38 & 36.905 .330 & 16,57 & 14.672 .126 & 47,07 & 57.581 .834 & 17,18 \\
\hline C. Valenciana & 8.144 .203 & 10,01 & 20.379 .385 & 9,15 & 4.849 .831 & 15,56 & 33.373 .419 & 9,96 \\
\hline Total & 78.730 .070 & 96,76 & 176.884 .540 & 79,44 & 23.577.993 & 75,64 & 279.192 .603 & 83,29 \\
\hline España & 81.363 .794 & 100 & 222.671 .466 & 100 & 31.171 .145 & 100 & 335.206 .405 & 100,00 \\
\hline
\end{tabular}

Fuente: Elaboración propia con datos de INE 2002a, 2002b y 2002c.

La importancia y centralidad del sur de Gran Canaria como destino turístico explica que el caso haya sido ya utilizado para realizar diversos estudios de caso, tanto sobre distintos aspectos de la organización de los recursos humanos (Marrero Rodríguez 1996, 2000 y 2003) como sobre la externalización de actividades productivas en el sector hotelero (Espino Rodríguez y Padrón Robaina 2004a, 2004b) o sobre la competitividad de ciertos subsectores turísticos (Melián González y García Falcón 2003). Por otra parte, la mera importancia cuantitativa de Maspalomas como localidad turística otorga relevancia cuantitativa a los resultados obtenidos. Según los datos de la Organización

Tirajana se realizaron en el año 2000 un total de 7.813.693 pernoctaciones. Como los establecimientos hoteleros representan aproximadamente un $25 \%$ de la oferta alojativa del municipio, si multiplicamos por cuatro las pernoctaciones hoteleras nos da un total de 31.254.772, es decir el 9\% del total de España. Pero dado que el índice de ocupación en los establecimientos extrahoteleros es menor que en los hoteleros, cabe pensar que la cifra no sea tan elevada. En cualquier caso, se puede estimar que el total de pernoctaciones en San Bartolomé de Tirajana en el año 2000 estuvo entre los 21 millones, cifra obtenida según la estimación anterior, y los 31 millones que se estiman por esta vía. Por ello hemos tomado como cifra intermedia la cantidad de 25 millones de pernoctaciones, lo que corresponde aproximadamente al 7,25\% del total de pernoctaciones de España. 
Tabla 3. La actividad turística en España: pernoctaciones totales por provincias y composición.

\begin{tabular}{|c|c|c|c|c|c|c|}
\hline & Pernotaciones & $\begin{array}{l}\% \\
\text { total }\end{array}$ & $\begin{array}{l}\% \\
\text { hoteles }\end{array}$ & $\begin{array}{l}\% \\
\text { apartamentos }\end{array}$ & $\begin{array}{l}\% \\
\text { cámping }\end{array}$ & $\begin{array}{l}\% \\
\text { extranjeros }\end{array}$ \\
\hline Baleares & 67.802 .146 & 19,64 & 78,80 & 20,97 & 10,24 & 90,71 \\
\hline Las Palmas de GC & 57.919 .228 & 16,77 & 35,29 & 64,69 & 0,02 & 92,93 \\
\hline Santa Cruz de TF & 32.183 .297 & 9,32 & 53,79 & 46,18 & 0,03 & 85,00 \\
\hline Alicante & 22.011 .600 & 6,38 & 65,88 & 24,20 & 9,92 & 60,90 \\
\hline Girona & 20.905 .657 & 6,05 & 54,96 & 11,92 & 33,12 & 70,61 \\
\hline Barcelona & 20.560 .218 & 5,95 & 82,36 & 2,72 & 14,93 & 62,66 \\
\hline Málaga & 20.237 .609 & 5,86 & 74,49 & 20,66 & 4,85 & 72,13 \\
\hline Madrid & 14.058 .504 & 4,07 & 90,02 & 5,32 & 4,66 & 47,78 \\
\hline Tarragona & 12.810 .989 & 3,71 & 51,74 & 21,79 & 26,47 & 59,24 \\
\hline Almería & 5.505 .241 & 1,59 & 74,73 & 15,10 & 10,17 & 55,39 \\
\hline Total provincias & 273.994 .489 & 79,35 & 45,07 & 25,31 & 6,76 & 57,08 \\
\hline Total España & 345.276 .914 & 100,00 & 65,79 & 25,89 & 8,32 & 45,29 \\
\hline
\end{tabular}

Fuente: elaboración propia con datos de INE 2001.

Mundial del Turismo, en 1996 un 60\% del turismo mundial se concentraba en los países de Europa (Sancho 1998). Según Díaz y Frutos (2003), para 1999 el $47 \%$ de los viajes de los europeos tenía como destino lo que denomina el Gran Mediterráneo, siendo España el destino más destacado con el 32\% de esos viajes. Dentro de España, Andalucía, Baleares, Comunidad Valenciana, Cataluña y Canarias concentraban para el año 2002 el 83,29\% de las pernoctaciones turísticas, siendo Canarias la principal concentración con más de un $25 \%$ del total. ${ }^{5}$ Conviene tener presente que Baleares y Canarias acaparan casi la mitad de la actividad turística española, acumulando cada una de ellas por separado tantos o más turistas que Portugal, Grecia, Turquía o Túnez, países que son por sí mismos auténticas potencias turísticas.

El turismo en Maspalomas comenzó a desarrollarse a partir de la mitad de los años sesenta, aunque es a partir de principios de los setenta cuando se da el definitivo despegue turístico. Se trata de un destino relativamente maduro, si bien no tanto como otros destinos del Mediterráneo, y que ha participado en los principales cambios acaecidos en el «turismo de masas» en los últimos treinta años. Es decir, el turismo en la localidad objeto de estudio cuenta ya con una tradición lo suficientemente larga como para haber pasado de una fase de despegue inicial a posteriores estancamientos e incluso crisis. El turismo en Maspalomas es relativamente poco estacional, con dos temporadas altas

5. Elaboración propia con datos facilitados por el Instituto Nacional de Estadística (INE $2002 a, 2002 b, 2002 c)$. 
(invierno y verano) y períodos intermedios entre ellas con una ocupación relativamente buena, lo que es similar a lo que sucede en otras localidades turísticas de Canarias y significativamente diferente del de otros destinos turísticos como los situados en el Mediterráneo, donde la temporada turística se concentra en los meses de verano. Desde el punto de vista de su desarrollo urbanístico, Maspalomas presenta un modelo relativamente atípico. Si bien muchos de los núcleos turísticos desarrollados con el boom del turismo de los sesenta representan un perfil marcado por altas torres de edificios de apartamentos y hoteles, el perfil urbanístico de Maspalomas es mucho más bajo, marcado por los complejos de bungalows y apartamentos. En relación con esto, el predominio de la oferta alojativa extrahotelera sobre la hotelera en Maspalomas constituye un caso extremo por comparación con lo que es habitual en otras localidades turísticas, ya que si bien en la mayoría de las zonas turísticas de Canarias existen más plazas extrahoteleras que hoteleras, es en Maspalomas donde este predominio es mayor. ${ }^{6}$ Ante todo aclararemos que el concepto de "establecimiento extrahotelero" en Canarias se entiende como un apartamento o bungalow legalmente establecido, con todas las correspondientes licencias de apertura y funcionamiento del Cabildo de la isla en que se encuentra y de la Consejería de Turismo del Gobierno de Canarias. Este establecimiento está compuesto por un número variable de unidades alojativas, que bien se encuentran en una edificación independiente y a pie de tierra (bungalow) o bien forman parte de un edificio (apartamento). Cada una de estas unidades alojativas dispone, a semejanza de una vivienda, de al menos una (o más) habitación-dormitorio (y en esto resulta similar a cualquier habitación de hotel), además de una zona de cocina- comedor y pequeño salón. Dispone también, en muchos casos, de una pequeña zona de terraza o jardín. Como han puesto de manifiesto autores como Marrero Rodríguez (1998), la gestión de este tipo de establecimientos se ha acercado muchísimo a la de un establecimiento hotelero. Así, todos estos establecimientos disponen cuando menos de una recepción, de un servicio de limpieza de las habitaciones y lavandería de sábanas y toallas (éstos son los servicios mínimos sin los cuales no obtendrían la correspondiente licencia). Además, la mayoría de ellos disponen de una pequeña tienda o supermercado, de uno o varios bar-restaurantecafetería, donde en muchos casos se sirven desayunos y/o cenas, y de servicios de animación y otros, como alquiler de coches. En definitiva, al hablar de «establecimiento extrahotelero» en Canarias se está haciendo referencia a un tipo de establecimiento que es, en lo esencial, similar a un establecimiento hotelero. La diferencia es que todos estos establecimientos disponen de facilidades para que los turistas preparen su propia comida (cocina, nevera, etc.), algo que no se encuentra nunca en un establecimiento hotelero, mientras que, por

6. Según los datos de Gobierno de Canarias, 2003b, para el año 2002 eran extrahoteleras el 74\% de las plazas alojativas de Lanzarote, el 69\% de las de Fuerteventura, el 74\% de Gran Canaria, el 45\% de Tenerife, el 72\% de La Palma, el 76\% de La Gomera y el 62\% de El Hierro. 
el contrario, no todos disponen de servicios de restauración (desayuno y cena, sobre todo, tan amplios como los de un hotel). ${ }^{7}$

La aproximación al estudio del caso de Maspalomas se ha realizado desde una metodología multiestratégica. En una primera fase de la investigación se realizaron entrevistas en profundidad sobre las trayectorias laborales, centradas en los mecanismos de reclutamiento de los empleados/as, de establecimiento de las cualificaciones y de los mecanismos de trasvase poblacional que explican que en poco más de 40 años Maspalomas haya pasado de ser una zona prácticamente desértica a ser uno de los polos de actividad económica y poblacional de la isla. Se realizaron 16 entrevistas, en dos establecimientos extrahoteleros, una cadena hotelera y dos testigos privilegiados. ${ }^{8}$

Los resultados de esta primera fase de la investigación permitieron contrastar las aportaciones de la literatura existente acerca de los mecanismos de reclutamiento en la industria turística. Marrero Rodríguez $(1998,2003)$ para el sur de Gran Canaria y Benítez Rochel y Robles Tegeiro (1992) para la Costa del Sol malagueña habían establecido que el recurso a las redes es el principal mecanismo de reclutamiento de la fuerza de trabajo, que esto se relaciona de manera muy estrecha con la construcción social de las cualificaciones y que es el recurso a las redes sociales lo que explica el origen geográfico de la población trabajadora en un entorno prácticamente despoblado antes del desarrollo turístico. Pero las entrevistas también permitieron poner de manifiesto un hecho al que hasta entonces no se le había otorgado pertinencia teórica. Aunque

7. Llegados aquí, querríamos hacer algunas precisiones acerca de las «segundas residencias». La importancia de la «segunda residencia» en el litoral mediterráneo español hace que en algunas comunidades, como Cataluña o la Comunidad Valenciana, las estadísticas de turismo incluyan también las segundas residencias. En realidad, el fenómeno de la segunda residencia tiene más que ver con la promoción inmobiliaria que con el turismo propiamente dicho (véase, por ejemplo, Mazón Martínez y Aledo Tur 2004). Y, especialmente desde el punto de vista que aquí nos interesa (el empleo), la segunda residencia, en cuanto incide en la generación de empleo sólo durante su construcción, afecta al empleo en el sector de la construcción y no del turismo.

8. Una exguía para varios touroperadores y una persona encargada de la gestión inmobiliaria de varios apartamentos. En el primero de los establecimientos, las entrevistas se organizaron a partir de la organización del trabajo en una empresa turística. Así, se realizaron entrevistas con trabajadores/as de los departamentos de administración, comedor, pisos, recepción, mantenimiento y jardinería. En el segundo de los establecimientos se realizaron tres entrevistas, al gerente, al recepcionista y a una guía de turismo receptivo. Estas entrevistas permitieron contrastar la información obtenida anteriormente, y comprobar que la organización del trabajo y el tipo de turismo era en lo fundamental similar a las del primer establecimiento. En la cadena hotelera se hizo una entrevista con un director adjunto comercial, así como con el director de un establecimiento. El hecho de que en esta cadena las entrevistas se realizaran con informantes pertenecientes a la dirección y no a trabajadores se explica porque el objetivo en este caso, más que conocer la organización del trabajo, de la que se tenía información por estudios anteriores (Marrero Rodríguez 1998) era conocer si el tipo de turismo era diferente, y por eso las entrevistas se centraron en la parte comercial (director adjunto comercial, director de un establecimiento). Por último, las entrevistas con los testigos privilegiados sirvieron para detectar cuestiones que resultarían claves en el desarrollo posterior de la investigación. 
la organización de la oferta turística en el sur de Gran Canaria se basa en la participación de un número relativamente amplio de medianas y pequeñas empresas, éstas, al menos en el sector alojativo extrahotelero, no se habían constituido mediante el capital aportado por un único capitalista, ya fuera éste una persona física o una familia. La construcción de la oferta turística alojativa en el sur de Gran Canaria se hizo en base al sistema de "venta sobre planos». Para la construcción de los complejos de bungalows o apartamentos que en la actualidad constituyen una parte central de la oferta de la localidad, miembros de las clases medias y profesionales de la isla invertían sus ahorros en la adquisición/construcción de uno (o varios) apartamentos o bungalows. La comunidad de propietarios de los apartamentos contrata la explotación hotelera/alojativa de las mismas a empresas de explotación hotelera, que en muchos casos han surgido de las propias comunidades de propietarios debido a los cambios en la legislación, aunque es preciso señalar que se trata de un procedimiento que ha variado con el tiempo. Como resultado final de este proceso nos encontramos con un tejido de pequeñas y medianas empresas que, en vez de haber sido el resultado de un número similar de pequeños y medianos capitalistas, es el resultado de la aportación de numerosos «microcapitalistas». Dado que el capital que poseen cada uno de manera individual, inmovilizado en forma de uno, dos o a lo sumo tres apartamentos, es inferior al que es necesario para poner en marcha la actividad turística, la actuación coordinada de varios propietarios, materializada en las comunidades de propietarios, resulta crucial para el desarrollo de la misma. De hecho, y ésta fue la principal conclusión de esta fase de la investigación, que la oferta turística correspondiera a esta tipología que acabamos de describir (las comunidades de propietarios) o bien a otro tipo de empresas parecía ser el factor que más influía en la calidad del empleo, más que cualquier otro de los considerados en la literatura acerca de las condiciones de empleo, tanto en la genérica como en la específicamente relacionada con el turismo. Mientras que autores como Harrison (1997), para el conjunto de sectores productivos, o Wanhill (2000), para el sector turístico, parecían señalar al tamaño de la empresa como la variable más influyente en la determinación de las condiciones laborales, los resultados de nuestra investigación parecían señalar que ésa podría ser una relación espuria, ya que lo que realmente estaría influyendo no sería el tamaño sino otro tipo de variables (como el tipo de propiedad) que habitualmente suelen correlacionarse con él.

Llegados a este punto, la investigación se orientó a la comprobación de si este sistema que acabamos de señalar era efectivamente el mayoritario en la localidad o si por el contrario se trataba de una relativa excepción. Para ello se llevó a cabo, en primer lugar, un estudio de los documentos de planeamiento urbanístico de la localidad. El análisis de los distintos proyectos de urbanización y ordenación permitió dar un sentido al fenómeno de la construcción sobre planos como mecanismo predominante de construcción. El proyecto surgido del concurso de ideas celebrado en 1960 para la urbanización de lo que hoy se conoce como Maspalomas presuponía la existencia de capitales, mayorita- 
riamente extranjeros, dispuestos a invertir en la actividad turística en la localidad. El Conde de la Vega Grande, entonces propietario de la totalidad del suelo de lo que hoy es la localidad turística, contemplaba en su diseño de urbanización parcelas, relativamente grandes, que se ponían a la venta con características de «suelo urbano» con capacidad para construir varias plantas. El análisis de las alegaciones presentadas a las Normas Subsidiarias del municipio de San Bartolomé de Tirajana permitió constatar un hecho sorprendente. Y es que la mayoría de las alegaciones iban en el sentido de rebajar las alturas de lo que se permitía construir, pidiendo que donde estaba previsto edificar hoteles de varias plantas se pudieran construir bungalows o apartamentos de menos plantas. Este hecho parecía incomprensible desde los enfoques tradicionales sobre la especulación inmobiliaria (véase Santana Santana 1993). Edificar en altura permite incrementar la superficie construida y, por tanto, más ganancia, tanto para el constructor como para la futura "empresa alojativa», que podrá "producir» más pernoctaciones turísticas por unidad de terreno consumido. El que en Maspalomas el interés fuera, justamente al contrario, el de reducir la altura de las construcciones, se explica a partir de la carencia de capitales. Hace falta un capital inicial mucho mayor para construir y poner en condiciones de funcionamiento un hotel que para un complejo de apartamentos o bungalows del tipo del que hemos señalado anteriormente. Tanto de las entrevistas como de la información obtenida mediante el análisis de los documentos de planeamiento se extraía la idea de que el desarrollo turístico de Maspalomas había estado marcado en sus inicios por la escasez de grandes capitales dispuestos a invertir. ${ }^{9}$

En cualquier caso, hay que señalar que el análisis de documentos de planeamiento urbanístico no permitió responder a la pregunta acerca de si las comunidades de propietarios seguían siendo aún un sistema de gestión de la ofer-

9. Las expectativas de ganancia económica del promotor de una urbanización turística se basan en la suposición de que hay capitales dispuestos a invertir en construcción y en transformar lo que hasta entonces eran costas más o menos vírgenes en urbanizaciones turísticas. Ésta era sin duda la pretensión del Conde de la Vega Grande al promover la urbanización de Maspalomas. Sin embargo, al cotejar los documentos de planeamiento con la fecha de apertura de los establecimientos alojativos, se constata que el lapso de tiempo entre ambos es excesivamente grande. Así, por ejemplo, en la zona de Playa del Inglés, cuyo proyecto de urbanización es de mediados de los años setenta, la mayoría de los establecimientos se abrieron unos cinco años después. En la zona del Campo de Golf-Campo Internacional, cuyo proyecto de urbanización es de principios de los años ochenta, la mayoría de los complejos se abrieron en la segunda mitad de la década. El período de tiempo, entre 5 y 10 años, es muy superior al necesario para construir físicamente y poner en funcionamiento los establecimientos alojativos. Por ello pensamos que es necesario entenderlo como un período de ajustamiento de unas expectativas demasiado elevadas por parte de los propietarios de los terrenos a la realidad de un mercado de "capitales» relativamente magro. En un primer lugar el propietario ponía en venta el terreno a un precio muy elevado, esperando que una potente compañía (foránea) adquiriese el terreno para construir y explotar un hotel. En vista de que ésta no llegaba, en muchos casos se optó finalmente por vender el terreno, a un precio inferior, a un constructor local, que lo dedicaba a la edificación de apartamentos o bungalows mediante el sistema de venta sobre planos. 
ta turística significativo en el momento de realizar la investigación. En cualquier caso, sí permitió constatar que efectivamente el sistema de venta sobre planos había sido el sistema mayoritario en la construcción de la planta alojativa de la localidad. Permitió también entender la importancia del capital (la abundancia o escasez de capital dispuesto a invertir en el sector turístico) en la determinación de la forma de una urbanización y acercarse a la comprensión sociológica de la forma de las urbanizaciones turísticas. ${ }^{10} \mathrm{~A}$ partir del análisis de los documentos del planeamiento y de otras fuentes utilizadas, puede afirmarse que este sistema de venta sobre planos fue ampliamente mayoritario durante los años setenta y ochenta, que fue el período en que se construyó el grueso de la planta alojativa de la localidad, ya que, hasta las nuevas construcciones en la zona de Meloneras, realizadas a principios del siglo XXI, apenas se realizaron nuevas edificaciones turísticas (alojativas) en Maspalomas en la década de 1990. Por otra parte, estos datos resultarían corroborados con los que veremos a continuación. El hecho de que en la actualidad, y después de que se hayan producido sin duda procesos de concentración de capitales, una gran parte de la oferta pertenece a comunidades de propietarios resulta congruente con el predominio de este sistema durante el período de constitución de la oferta que estamos comentando.

La última fase de la investigación, dada la imposibilidad de conseguir los datos por otras fuentes, se centró en la elaboración y aplicación de una encuesta a los establecimientos extrahoteleros de Maspalomas para conocer datos tanto acerca de la tipología de la gestión (si había comunidades de propietarios o no) como de las características del empleo y otras variables. Dado que en fases anteriores de la investigación se había constatado la dificultad para acceder a muchos datos si éstos no se solicitaban por la vía adecuada, se optó por contactar con la federación de empresarios alojativos. Cotejando la base de datos de afiliados de esta federación con las que las distintas administraciones disponían de establecimientos alojativos oficialmente abiertos, se llegó a la conclusión de que la federación agrupaba a la gran mayoría de empresas del sector y que centrando el análisis en las empresas afiliadas no se estaba sesgando en exceso la muestra. Así pues, se encuestaron a 179 de los 405 establecimientos extrahoteleros existentes en la localidad (según las cifras del Instituto Canario de Estadística para la fecha de referencia). Ello representa un total de 45.355 plazas alojativas sobre el total de 76.279 plazas alojativas extrahoteleras con que contaba Maspalomas en el momento de realizar el trabajo de campo, es decir, casi un 60\%. La encuesta, cuya duración estaba en

10. En el sentido que aquí estamos señalando, el urbanismo turístico de Lloret de Mar, Benidorm o Calvià es la plasmación física de sociedades con capas relativamente amplias de clases medias propietarias dispuestas a invertir en la actividad turística. El de localidades como Marbella, Torremolinos o ciertas zonas de Tenerife sería la plasmación de un equilibrio en que un papel menor representado por las clases propietarias locales (menos fuertes) se vería compensado por la abundancia de capital proveniente del exterior y dispuesto a invertir en ellas. Por último, Maspalomas sería un caso extremo de escasez de capitales. 
torno a los 30 minutos, ${ }^{11}$ se dividía en tres bloques. El primero incluía preguntas acerca del tipo de gestión, la pertenencia o no a cadenas, los cambios en la gestión y las características de la propiedad (por ejemplo, si el complejo era propiedad de una comunidad de propietarios, de un empresario individual o de una sociedad). El segundo preguntaba acerca del tipo de turistas del establecimiento y la evolución de los mismos, así como los tipos de contrato (de relación) que se establecían entre los establecimientos y los touroperadores con los que se trabajaba. El tercero de los bloques incluía preguntas acerca de las características socio-demográficas de los empleados, el origen geográfico de los mismos y la estabilidad en el empleo. Por último, además de estos tres bloques, que resultaban cruciales para los objetivos de la investigación, se incluyeron también en la encuesta otras cuestiones acerca de la aplicación de sistemas de calidad, normativa antiincendios y sistemas de prevención de riesgos laborales.

El análisis de los datos obtenidos de la encuesta se centró en el establecimiento de las frecuencias de las variables cruciales y en las tablas de contingencia entre las variables explicativas de la investigación. Además, durante todo el proceso de la investigación, los datos obtenidos se fueron contrastando con otras fuentes secundarias. Además del análisis de todas las fuentes estadísticas disponibles, se llevó a cabo también un análisis de la propaganda turística, así como el seguimiento de todas las informaciones aparecidas en prensa en relación al objeto de la investigación.

\section{Organización de la oferta turística en Maspalomas}

Con esta investigación pretendíamos acercarnos al conocimiento de los factores que influyen en la "calidad» del empleo creado por el desarrollo turístico. Como cuestión subsidiaria de ésta, queríamos contrastar si la tan extendida idea de que el mejor modelo de desarrollo turístico para una localidad es el que se basa en la construcción de alojamientos hoteleros de «calidad», medida ésta según el número de estrellas, tiene fundamentos empíricos o se trata quizá de un "lugar común», de engañosa y casi intuitiva veracidad. Dado que el empleo ha sido tradicionalmente contemplado como la principal consecuencia socio-económica del turismo, la investigación entronca con el debate acerca de si el turismo contribuye o no al desarrollo socio-económico de una comunidad o por el contrario es una nueva forma de neocolonialismo o dependencia

11. La duración de la entrevista y el carácter conflictivo de algunas de las preguntas a realizar fueron dos motivos por los que se optó por entrar a través de una federación empresarial, pues cierta relación de confianza era esencial para la validez de la información obtenida. Todas las entrevistas se hicieron personalmente por el autor de esta investigación, sin que se subcontratara ninguna de las tareas que conllevó la elaboración de la encuesta (trabajo de campo, introducción de datos y análisis). Por ello, el que en más de una ocasión los entrevistados se explayaron durante bastante más tiempo del que señalamos anteriormente permitió obtener una información muy útil para los objetivos de la investigación. 
que, justo al contrario, constituye un freno más que una ayuda para el «desarrollo» (Rubio Gil 2003; Santana Talavera 1997; Turner y Ash 1991). Ahora bien, tanto las dificultades encontradas a la hora de acceder a la información como los «hallazgos» encontrados en el transcurso de la investigación obligan a exponer algunos resultados intermedios de la investigación antes de proceder a hablar sobre la relación entre el desarrollo turístico y «calidad» del empleo.

Respecto a la importancia del sistema de "comunidades de propietarios» en la configuración de la oferta alojativa de la comunidad, cabe afirmar que a partir de los resultados de la investigación se ha estimado que unas 55.000 plazas, es decir, el $72 \%$ de las plazas extrahoteleras y más del $55 \%$ de las plazas alojativas, están en manos de comunidades de propietarios. La importancia de estas cifras hace que, como ya planteáramos anteriormente, este sistema deba ser tenido en cuenta como un hecho no meramente marginal al fenómeno turístico. Basta pensar que son relativamente pocas las localidades turísticas en el mundo que concentran 55.000 o más plazas turísticas. Si entramos a analizar las características de los propietarios, a partir de los resultados de la encuesta se estimó que más de 13.000 apartamentos o bungalows pertenecen a pequeños propietarios. Y dado que éstos poseen por lo general un número relativamente pequeño de unidades, puede estimarse que existen en torno a 10.000 pequeños propietarios en la localidad. En cuanto a su origen geográfico, en base a los resultados de la encuesta se puede afirmar que en torno a un $74 \%$ de los propietarios son locales (de la isla de Gran Canaria), un 16\% de origen germánico (alemanes y en menor medida austríacos y suizos) y un $7 \%$ de origen nórdico.

Estos datos nos llevan sin duda a entrar en diálogo con las teorías sobre el desarrollo turístico. Existe una idea, bastante generalizada en muchas comunidades turísticas, según la cual el turismo no es beneficioso para las mismas pues los beneficios de la actividad se van fuera, ya que los mejores empleos son ocupados por foráneos y las rentas empresariales se van también fuera al ser los capitalistas externos. Del empleo ya hablaremos más adelante. En cuanto al capital, lo que se deriva de nuestra investigación es que, al menos para el caso de Maspalomas, esta afirmación no debería hacerse tan alegremente, de manera que planteamientos como los de Turner y Ash (1991), Jurdao Arrones (1992) o Gaviria (1978) acerca del turismo como forma de neocolonialismo difícilmente pueden aplicarse, al menos, al caso del sur de Gran Canaria. Cierto es que una parte importante de las plazas hoteleras en la zona es propiedad de cadenas internacionales, pero el grueso de la oferta, que es extrahotelera, es de propiedad local. Por tanto, difícilmente pueden mantenerse afirmaciones del tipo de «en realidad el negocio lo hacen los grandes capitales transnacionales» cuando más de la mitad de las plazas son propiedad de pequeños propietarios locales. Obviamente, podría argumentarse que la importancia de las comunidades de propietarios podría ser un fenómeno excepcional propio tan sólo de Maspalomas. Al respecto pensamos que es sin duda necesario intentar estudiar el fenómeno en otros destinos turísticos. Existen sin embargo elementos para pensar que este fenómeno se ha dado también, si 
bien en medida quizá algo menor, en el resto de localidades turísticas de Canarias. Y dada la importancia de Canarias en el turismo mundial, pensamos que difícilmente se puede menospreciar este fenómeno como una «excepción que confirma la regla».

Quedaría en cualquier caso por responder la pregunta acerca de por qué ha alcanzado tanta extensión la idea de que el turismo ofrece a las comunidades receptoras pocas posibilidades para un verdadero desarrollo socio-económico. A título de hipótesis nos atrevemos aquí a plantear que el que las «teorías de la dependencia» hayan tenido tanto éxito en su aplicación al turismo tendría que ver con que es una explicación que resulta conveniente también para las clases dominantes locales, ya que permite soslayar la cuestión del reparto social de la riqueza generada por la actividad turística en destino. Si se extiende la idea de que no se ha creado riqueza, no hay nada que repartir, y por tanto se elude una cuestión clave. En este contexto, quizá los agentes exteriores a las comunidades turísticas, como los touroperadores, se convierten en chivos expiatorios. En cualquier caso, centrándonos tan sólo en el empleo, el objetivo que nos planteábamos en esta investigación era conocer los factores que influyen en la calidad del empleo turístico. Y también saber si, dado que al parecer produce más y mejores empleos, un modelo turístico basado en los establecimientos hoteleros de «calidad» debería ser potenciado por las autoridades locales en detrimento de otro modelo turístico demonizado como «de masas».

\section{Factores que inciden en la calidad del empleo turístico}

Por todo lo que hemos puesto de manifiesto hasta aquí, el estudio del modelo de Maspalomas permitió en primer lugar plantear en términos más adecuados el debate acerca de cómo reconducir el turismo de un destino hacia modelos que favorecieran en mayor medida a las comunidades locales. A la hora de evaluar la «bondad» de un modelo de desarrollo turístico hay que tener en cuenta no sólo los empleos, sino también las rentas que genera. Pero, además, y ese era nuestro objetivo inicial, la investigación permitió obtener algunos resultados acerca de los factores que condicionan la «calidad» del empleo turístico. En primer lugar, siguiendo con el debate entre el turismo como "pasaporte para el desarrollo» o bien como una nueva forma de «neocolonialismo" una pregunta clave acerca del empleo turístico es la de qué explica las características socio-demográficas del empleo en el sector. Diversos autores han constatado que el empleo en el sector suele ser relativamente descualificado, mal remunerado, inestable y feminizado (Santana Talavera 1997; Brunet y Belzunegui 2003). Además, suele suceder que los mejores empleos del sector turístico no los ocupan miembros de las localidades turísticas sino que los ocupan trabajadores que vienen de fuera. Ahora bien, como señala Santana Talavera (1997), podría suceder que esas condiciones fueran tan sólo el resultado de una fase inicial del desarrollo turístico y no de algo intrínseco al sector. Según los datos que se derivan de la encuesta, de los cerca de 15.000 empleos que existen del sector de hostelería en la localidad, aproximadamente unos 
Tabla 4. Oferta alojativa y empleo.

\begin{tabular}{|c|c|c|c|c|c|c|c|c|c|c|}
\hline & \multicolumn{5}{|c|}{ Oferta extrahotelera } & \multicolumn{5}{|c|}{ Oferta hotelera } \\
\hline & Plazas & $\%$ & Empleos & $\%$ & Pl./empl. & Plazas & $\%$ & Empleos & $\%$ & Pl./empl. \\
\hline España & 566.861 & 100 & 27.017 & 100 & 20,98 & 1.315 .697 & 100 & 143.734 & 100 & 9,15 \\
\hline Baleares & 110.683 & 19,53 & 4.000 & 14,81 & 27,67 & 314.666 & 23,92 & 25.258 & 17,57 & 12,46 \\
\hline Canarias & 241.080 & 42,53 & 17.458 & 64,62 & 13,81 & 143.300 & 10,89 & 25.419 & 17,68 & 5,64 \\
\hline S. Bartolomé T & 76.296 & 13,46 & 5.063 & 18,74 & 15,07 & 21.720 & 1,65 & 5.098 & 3,55 & 4,26 \\
\hline
\end{tabular}

Fuente: Elaboración propia con datos de INE 2001, 2003 y encuesta propia. Los datos de los apartamentos se han extraído del "Análisis de la ocupación de los alojamientos turísticos de España» (INE 2001), salvo los de Maspalomas, que se han estimado a partir de la encuesta. Los datos de los establecimientos hoteleros se han extraído de la Encuesta de Ocupación Hotelera llevada a cabo por el INE.

5.000 corresponden al sector alojativo extrahotelero. ${ }^{12}$ Más de la mitad de ese empleo $(57 \%)$ es ocupado por mujeres, en su inmensa mayoría (80\%) por trabajadoras/es con bajo nivel de cualificación formal (estudios básicos). Y sin embargo, cerca del 65\% de los empleos tienen carácter fijo frente a un 35\% de eventuales. Estos datos contrastan con las cifras de la Encuesta de Apartamentos Turísticos del INE para Canarias y para el conjunto del Estado, que invierten los porcentajes (mayoría de trabajadores eventuales).

En definitiva, al menos si hacemos referencia a la estabilidad en el empleo, parece que puede afirmarse que la «calidad» del empleo en el sector alojativo extrahotelero es mayor en Maspalomas que en otras localidades turísticas. Las posibles explicaciones para esto, en definitiva, los factores que condicionan la "calidad" del empleo son fundamentalmente tres, la primera relacionada con la situación temporal del destino de Maspalomas en la evolución del turismo, la segunda con su situación «espacial» relativamente central en el mercado y la tercera con la estabilidad y las características del turismo. Al hablar de la situación temporal de Maspalomas en la evolución del turismo, lo que estamos afirmando es que se trata de un destino turístico que inició su desarrollo en un momento en que, al menos en España, la legislación laboral era más rígida que la actual, por lo que gran parte de la fuerza de trabajo fue contratada en unas condiciones de estabilidad que, dado que las crisis en el sector no han sido tan importantes como para cerrar la mayor parte de la planta alojativa, aún mantienen. Al hablar de la situación «espacial» relativamente central de Maspalomas en el mercado, a lo que estamos haciendo referencia es que, dado que Canarias en general, y Maspalomas en particular, representan una parte

12. El resto del empleo se reparte de manera bastante equitativa entre el subsector hotelero y el de bares, cafeterías y restaurantes (uno 5.000 empleos cada uno). Si tenemos en cuenta que las plazas extrahoteleras (76.296) son muchas más que las hoteleras (21.270), es evidente que también en Maspalomas el sector hotelero genera muchos más empleos directos que el extrahotelero, lo cual se explica perfectamente si tenemos en cuenta los servicios que oferta cada sector a los turistas. 
tan importante del negocio de los principales touroperadores europeos (en torno al $25 \%$ en la temporada de invierno), éstos son los primeros interesados en mantener unos ciertos niveles de ocupación, lo que acaba repercutiendo en la gestión de la mano de obra. Así, la presión en los precios que pueden ejercer los touroperadores sobre destinos nuevos y emergentes (por ejemplo, algunas zonas del Caribe o el sudeste asiático) es mayor, planteando la negociación en términos de "o me ofertan buenos precios o no les incluyo en mi catálogo». Por el contrario, la situación central de Canarias como destino turístico obliga a los touroperadores a un tipo de relación diferente, ya que son conscientes de que han de llegar a algún tipo de acuerdo sin poder amenazar con, simplemente, no ofertar el destino. El razonamiento vendría a ser más o menos el siguiente. Si no hay acuerdo (por los precios) entre los touroperadores y la oferta alojativa de un destino emergente, es éste nuevo destino el que sale perdiendo, ya que los turistas (de los mercados alemán, británico o nórdico), sencillamente no irán a ese destino porque no aparece en el catálogo del touroperador. Por el contrario, si un touroperador decide no incluir a Canarias, o a una zona tan importante como Maspalomas en su catálogo, es el touroperador el que "saldría perdiendo», ya que se trata de un destino como una «imagen de marca» tan fuerte que un número significativo de turistas cambiaría de touroperador, o reservaría su viaje de manera directa pero seguiría siendo «fiel» a su destino. Por último, al hablar de la estabilidad y las características del turismo, lo que estamos planteando es que el hecho de que el turismo en Maspalomas sea relativamente estable a lo largo de todo el año, y no estacional como sucede en otros destinos (fundamentalmente en el Mediterráneo), incide sin duda en el hecho de que el empleo en el turismo sea más estable que en otros destinos.

\subsection{Las «rigideces institucionales»}

Como acabamos de señalar, autores como Santana (1997) plantean que la mala "calidad» del empleo turístico puede ser tan sólo un fenómeno de las fases iniciales del desarrollo turístico. En ese sentido, cabe suponer que en la medida en que el turismo fuera evolucionando se pasaría hacia un turismo de «mayor calidad", con unos empleos que implicarían mayores requerimientos de cualificación y mejores condiciones laborales. Sin embargo, la experiencia empírica obtenida en el análisis de la oferta turística de Maspalomas no permitiría mantener esta idea. Lo que sucede en la localidad es que, justamente al contrario, son los establecimientos más antiguos (y los trabajadores con más antigüedad en la zona) los que disfrutan de mejores condiciones laborales, medida fundamentalmente en términos de estabilidad en empleo. Según se desprende de las entrevistas realizadas, esto se explica básicamente por el momento en que tiene lugar la apertura de cada establecimiento: los complejos que abrieron sus puertas en los años 70 y primeros 80 lo hicieron en un contexto en que la legislación laboral era más rígida que la actual, y por tanto las contrataciones eran casi todas de trabajadores fijos y a ellas se les aplicaban los mecanismos típi- 
cos de la relaciones de empleo fordistas (promoción por antigüedad, por ejemplo). Por el contrario, los establecimientos abiertos en los últimos años se han encontrado una legislación laboral mucho más flexible, que de alguna manera favorece unas peores condiciones laborales. En este sentido, si la calidad del empleo en el sector extrahotelero de Maspalomas puede considerarse mayor que la de otros destinos es sencillamente porque el sector es más antiguo y se consolidó en un momento en que la legislación laboral era más «rígida». ${ }^{13}$ Lo que estamos planteando respecto a las «rigideces institucionales» como condicionante de la calidad del empleo no constituye en realidad ninguna novedad, ya que ha sido ampliamente tratado por la sociología del trabajo institucionalista. Sin embargo, pensamos que estos planteamientos han sido poco tenidos en cuenta en los análisis de la actividad turística hasta ahora realizados.

\subsection{La posición en la red}

Ahora bien, pese a la importancia que el período histórico pueda tener en la determinación de la calidad del empleo, lo que quizá puede considerarse el principal «hallazgo» de la investigación es que también en el sector turístico la posición de una empresa o conjunto de empresas en la red internacional de empresas que elaboran un determinado bien o servicio determina más la «calidad» del empleo que cualquier otro factor. Esta idea, aplicada al sector turístico, coincide con lo que autores como Castillo (1989) o Castells (2000) han encontrado en otros sectores productivos. Al constatar que los datos de la encuesta (y en general los de toda la investigación) ofrecían una imagen de la calidad del empleo extrahotelero de Maspalomas significativamente mejor de la que se podía deducir de los datos de la Encuesta de Apartamentos Turísticos del INE para otras zonas turísticas, se hizo pertinente poner en relación ese hecho con el distinto papel que desempeña la oferta extrahotelera en cada destino turístico. En Maspalomas la planta alojativa extrahotelera tiene un papel central en la oferta turística, y por ello la «calidad» del empleo en la misma es la propia de unos empleos que resultan centrales en el entramado económico de una localidad. Sin embargo, en otras zonas turísticas (especialmente fuera de Canarias), la planta alojativa extrahotelera es periférica al grueso de la oferta turística, que es fundamentalmente hotelera. Es por ello que la calidad del

13. Sin salir de Canarias, las primeras fases del desarrollo turístico de Maspalomas son contemporáneas de las primeras fases del desarrollo turístico del Puerto de la Cruz (Tenerife), cuya planta alojativa es fundamentalmente hotelera. El desarrollo turístico de buena parte del sur de Tenerife, así como varias zonas turísticas de Fuerteventura y Lanzarote es algo posterior. Si aplicamos la idea de que es la época de apertura del establecimiento lo que más condiciona la estabilidad, resultaría que las condiciones del Puerto de la Cruz deberían de ser similares a las de ciertas zonas de Maspalomas por corresponder al mismo período histórico, pese a la diferente tipología constructiva (hoteles- apartamentos). Por el contrario, aunque el tipo de alojamiento pueda ser similar en zonas de construcción más reciente, el período temporal marcaría la diferencia en cuanto a las condiciones de estabilidad y remuneración. 
empleo en el subsector extrahotelero es la propia de un sector que resulta periférico para el sistema económico de la localidad. Para profundizar más en esta idea se analizó, para los complejos estudiados en la encuesta, la relación entre la posición de cada establecimiento en el sistema turístico y los tipos de empleo. Como indicador de la posición en el sistema turístico se utilizó el tipo de contrato entre cada establecimiento y los touroperadores. Simplificando puede afirmarse que básicamente existen dos tipos de contratos entre los establecimientos alojativos y los touroperadores, en garantía y por cupos. En el primero de los tipos el touroperador compra al establecimiento alojativo un número significativo de noches al empezar la temporada turística, y las paga por adelantado, independientemente de que se ocupen o no. En definitiva, este tipo de contrato es un reflejo de una situación en la que el touroperador tiene interés en poder ofrecer a sus clientes un "producto" (el establecimiento) que es muy demandado y que por tanto puede afirmarse que resulta central en el sistema turístico. Por el contrario, en un sistema por cupos el touroperador sólo paga por las pernoctaciones que efectivamente realizan sus clientes.

Pues bien, de los resultados de la encuesta se deduce que en los establecimientos que se relacionan con los touroperadores a través de contratos por cupos, el número de empleos para los cuales se recurre a empresas de trabajo temporal es significativamente mayor que el de los establecimientos en que predominan los contratos en garantía. Por el contrario, en estos establecimientos los empleados fijos son comparativamente más numerosos de lo que lo son en los establecimientos que funcionan mediante contratos por cupos. Los resultados que se deducen de esta tabla han de ser matizados por el número relativamente pequeño de casos que se incluye en cada categoría, lo que resta representatividad estadística a los mismos (que, en cualquier caso, nunca se ha pretendido). Por tanto, deben ser tomados más como señal de unas determinadas tendencias que como cifras inamovibles. En este sentido, pensamos que es importante el hecho de que los empleos cubiertos a través de las ETTs sean el doble en las empresas que tienen contratos por cupos que en aquellas otras en que existen contratos en garantía. En definitiva, parece que la posición central o no de una empresa (y de una red de empresas) en la red de elaboración de servicios turísticos condicionan más las condiciones laborales que el tamaño de la empresa.

Este mismo tipo de razonamiento podría extenderse también para argumentar acerca de la mayor estabilidad del empleo turístico en Maspalomas (y en general en Canarias) en comparación con otros destinos. Según se desprende del análisis de los catálogos de los touroperadores más importantes de la Unión Europea, ${ }^{14}$ a principios del siglo XXI Canarias es un destino central para el mercado turístico. Concentra cerca de una cuarta parte del mercado total de invierno, y una parte no despreciable del de verano. En definitiva, la idea de que la

14. Mercados alemán, británico y nórdico. Ver Vallejo (2002), Schlueter Parrila (2002) y Santana Sánchez (2002). 
Tabla 5. Empleos según tipo de contrato y tipo de contrato del establecimiento con el TO.

\begin{tabular}{|c|c|c|c|c|c|c|c|c|c|}
\hline & \multicolumn{4}{|c|}{ Absoluto } & \multirow[b]{2}{*}{ Total } & \multicolumn{4}{|c|}{ Porcentaje } \\
\hline & Fijos & Eventuales & ETTs & Autónomos & & Fijos & Eventuales & ETTs & Autónomos \\
\hline Sin información & 225 & 152 & 10 & 0 & 387 & 58,14 & 39,28 & 2,58 & 0,00 \\
\hline En garantía & 739 & 307 & 54 & 6 & 1.106 & 66,82 & 27,76 & 4,88 & 0,54 \\
\hline Por cupos & 196 & 96 & 39 & 0 & 331 & 59,21 & 29,00 & 11,78 & 0,00 \\
\hline Otro tipo & 44 & 47 & 2 & 0 & 93 & 47,31 & 50,54 & 2,15 & 0,00 \\
\hline Time Sharing & 22 & 6 & 2 & 0 & 30 & 73,33 & 20,00 & 6,67 & 0,00 \\
\hline Total & 1.226 & 608 & 107 & 6 & 1.947 & 62,97 & 31,23 & 5,50 & 0,31 \\
\hline
\end{tabular}

Fuente: Elaboración propia con datos de la encuesta.

posición de cada empresa o localidad turística en la red internacional de elaboración de servicios turísticos condiciona más que cualquier otro factor las condiciones de empleo nos permitiría entender que si en Maspalomas (o en Canarias en general) las condiciones de empleo pueden ser mejores que las que se dan en otros destinos turísticos, ello es debido a que su posición en el mercado turístico es también más central.

\subsection{La estabilidad de la demanda}

Un factor que influye de manera decisiva en lo que acabamos de ver acerca de la posición "central» de Maspalomas y de Canarias en general en el mercado turístico es la importancia del turismo de invierno en las islas. En Maspalomas (y en realidad en prácticamente todas las localidades turísticas de Canarias), el turismo comenzó siendo un fenómeno de invierno. Los nórdicos y alemanes acudían a la localidad huyendo del frío de sus lugares de origen entre los meses de noviembre y marzo. Y este sigue siendo el perfil fundamental de los turistas nórdicos que acuden a Gran Canaria. Sin embargo, con el transcurso del tiempo se ha estabilizado la demanda turística a lo largo de todo el año, existiendo en la actualidad básicamente dos tipos de turismo que visitan la localidad. Por un lado un turismo de invierno, compuesto mayoritariamente de nórdicos y alemanes que visitan las islas con el objetivo ya señalado de «refugiarse del frío» y, por otro, un turismo de verano, compuesto además de alemanes por un grupo muy numeroso de turistas británicos e irlandeses ${ }^{15}$.

Pues bien, aunque la idea parece tan intuitiva y evidente que muchas veces tiende a pasarse por alto, existe relación entre la estabilidad de la demanda turística y la del empleo en el sector. Esta idea ha sido tratada con detalle en otros

15. Grupo que desde una posición relativamente marginal en los inicios del desarrollo turístico de la localidad han llegado a consolidarse como el grupo más numeroso, por ejemplo, en el verano de 2001. 
sectores económicos, donde quizá no parezca tan evidente, desde la aportación de Piore y Sable (1989) y posteriormente, de manera más o menos directa, por toda la literatura sobre la especialización flexible y los distritos industriales. En definitiva, si decimos aquí que si el empleo en el turismo de Maspalomas (y en general de Canarias) es, en líneas generales, más estable que en otros destinos turísticos es porque la demanda turística es también más estable en las islas que en otros destinos como, por ejemplo, los mediterráneos, puede parecer una perogrullada. Sin embargo, quizá por evidente, esta idea no ha recibido la atención que se merece en el sector turístico. Así por ejemplo, con frecuencia se presentan a determinadas formas de consumo turístico supuestamente "de calidad» como la panacea para cualquier destino, sin tener en cuenta su estacionalidad. Es el caso, por ejemplo, del turismo náutico, que se presenta en las mismas Directrices de Ordenación del Turismo del Gobierno de Canarias como una importante vía de "cualificación» de los destinos turísticos maduros sin tener en cuenta que se trata de un tipo de turismo que varía, nunca mejor dicho, en función del viento que sople. ${ }^{16}$

\section{Redes sociales y origen geográfico de los empleados}

El último de los factores que condicionan la calidad del empleo turístico sobre el cual el estudio del caso de Maspalomas ha permitido arrojar ciertos resultados es el de los mecanismos que determinan el origen geográfico de quienes acceden a los empleos que genera el turismo. Como ya hemos visto, algunos autores han señalado que en muchos casos los mejores empleos de la industria turística son ocupados por personas ajenas a las localidades en que ésta se desarrolla. En relación a la visión pesimista del desarrollo turístico, relacionadas de forma más o menos directa con las teorías de la dependencia, el hecho de que, por ejemplo en Canarias, muchos de los puestos que requieren más cualificación sean ocupados por personas del extranjero o del resto de España se ha visto como una nueva forma de colonialismo.

El turismo de sol y playa, casi por definición, se desarrolla en lugares en que la actividad humana era bastante escasa hasta que éste se empieza a desarrollar. Así por ejemplo, en Canarias el turismo se ha desarrollado fundamentalmente en localidades situadas al sur de las islas, como Maspalomas, que hasta entonces estaban prácticamente despobladas. Por tanto, no se da tan sólo el trasvase de la población activa de otros sectores al turismo, sino también, y de manera muy importante, su incremento, tanto mediante tasas de actividad más altas como mediante la inmigración. En el momento en que iniciamos esta investigación, diversos autores habían ya establecido que el recurso a las redes sociales es el principal mecanismo de reclutamiento de la mano de obra que accede al sector turístico, tanto para el caso de Maspalomas (Marrero

16. En Canarias, la temporada buena para la vela coincide con la de los vientos alisios, que no abarca todo el año. 
Rodríguez 1998) como para otros destinos turísticos como la Costa del Sol malagueña (Benítez Rochel y Robles Teigeiro 1992). Esto es, que el sector turístico no constituía una excepción a lo que otros autores habían planteado ya para el conjunto del mercado de trabajo en España (Requeña Santos 1991). Por tanto, parecía bastante claro que para establecer los mecanismos que permiten comprender por qué los empleos que genera la industria turística en una localidad son ocupados por personas que provienen de lugares distantes tan sólo unos kilómetros de la misma o distancias mucho mayores era necesario tirar del hilo de las redes de acceso a los empleos.

$\mathrm{Al}$ analizar la propiedad de la planta alojativa extrahotelera que está en manos de comunidades de propietarios, y una vez obtenida la estimación de que en torno al $75 \%$ de la misma pertenece a pequeños propietarios locales, el recurso a las redes permite comprender por qué los empleos de la industria turística de Maspalomas han sido mayoritariamente ocupados por personas provenientes de la comarcara sureste de Gran Canaria. Si quienes ponían en marcha la actividad turística en la localidad procedían de Gran Canaria, es lógico que, al recurrir a sus redes para ocupar las necesidades de personal, éstas les llevaran a contratar mayoritariamente personas de la isla. Al igual que sucedía al hablar de la relación entre estabilidad de la demanda y del empleo turístico, es una relación aparentemente tan intuitiva que puede fácilmente pasarse por alto.

El que la mayoría de las personas ocupadas en el sector turístico de Gran Canaria provengan de esa isla puede parecer algo normal y por tanto no digno de nuestra atención. Sin embargo, un análisis de la composición de la población de los municipios turísticos del mediterráneo demuestra que lo que nos parecía algo obvio es en realidad un hecho bastante extraordinario. La mayoría de la población (y estamos hablando de población total y no tan sólo activa) de Benidorm, Lloret de Mar o Calvià ha nacido, aún en la actualidad, fuera de la propia comunidad autónoma. Si analizamos el caso de los municipios turísticos canarios, las cifras son aún más sugestivas. Dejando de lado el caso del Puerto de la Cruz, existe una relación casi lineal entre el porcentaje de población de cada municipio turístico que ha nacido en Canarias y el reparto de las plazas alojativas entre hoteleras y extrahoteleras. Esto es, en los municipios de desarrollo turístico más reciente y centrado en el sector hotelero, entre un 50\% (Adeje) y un 61\% (Pájara) de la población a enero de 2001 había nacido fuera de Canarias (bien sea en el resto del Estado o en el extranjero). Por el contrario, donde la planta alojativa extrahotelera es mayoritaria, también la población nacida en Canarias es mayoritaria. ${ }^{17}$

17. Los municipios turísticos de Canarias con mayor porcentaje de población nacida en el archipiélago eran entonces Teguise (Lanzarote) y San Bartolomé de Tirajana (Gran Canaria), que son también donde más importancia ha tenido históricamente la planta extrahotelera. Las fuentes utilizadas para sostener estas afirmaciones son las cifras oficiales de población y de establecimientos alojativos, provenientes del INE y del ISTAC (Instituto Canario de Estadística). Una vez más, para un análisis detallado de las mismas nos remitimos a la tesis de la cual se nutre este trabajo (Santana Turégano 2003). 
Si relacionamos estas cifras con las de la propiedad, podemos hacernos una idea del mecanismo que explica el origen geográfico de la población empleada en el turismo. Allí donde éste es puesto en marcha por capital extranjero, es muy probable que los empleos acaben siendo ocupados por personas provenientes del exterior. Por el contrario, allí donde el turismo sigue un modelo de desarrollo más endógeno, a partir de los recursos de capital (y trabajo) de la comunidad local ampliada (en este caso, al conjunto de la isla o de las islas), es más probable que los empleos acaben siendo ocupados por locales. En definitiva, a la cuestión acerca de por qué muchos de los empleos generados por el turismo no revierten en la comunidad local se le podría responder, siquiera de manera parcial, que esto es así porque esos empleos son generados y su ocupación decidida desde agentes externos a la comunidad local. Los mecanismos que llevan a los empleadores en un sistema de pequeñas y medianas empresas como es Maspalomas a contratar a miembros de la comunidad local no han sido en sentido estricto el objetivo de esta investigación, pero pensamos que lo que ya se ha tratado de manera muy extensa para los distritos industriales de la tercera Italia puede aplicarse también a estas agrupaciones de empresas turísticas. Señalaremos tan sólo que, como ya han puesto de manifiesto críticos del paradigma de mercado como Mingione (1994), las relaciones de confianza y reciprocidad previas al desarrollo económico no suponen siempre un impedimento al mismo, sino, antes al contrario, una base de sociabilidad indispensable para desarrollar cualquier tipo de actividad económica.

\section{Conclusiones}

En este trabajo pretendíamos contribuir al análisis de los factores que influyen en la calidad (no sólo en la cantidad) del empleo generado por el desarrollo turístico. A partir del estudio del caso de Maspalomas, la primera conclusión a la que hemos llegado es la de que el estudio de las repercusiones socio-económicas no debe limitarse tan sólo al empleo que se crea, sino también a las rentas generadas. En el caso analizado, Maspalomas, puede estimarse que el número de pequeños propietarios de la planta alojativa extrahotelera, que está en torno a los 10.000 , es casi tan importante como el empleo directo generado por el turismo (15.000 empleos en el sector de hostelería en la localidad). Además de contribuir a situar más adecuadamente la importancia del empleo turístico, la investigación realizada también ha contribuido a identificar cuatro factores que parecen influir en la calidad del empleo generado por el turismo. De manera genérica puede afirmarse que estos cuatro factores implican una «disminución» de la especificidad del fenómeno turístico como factor de desarrollo. Como veremos a continuación, lo que diremos es que la calidad del empleo turístico no dependerá tanto de factores intrínsecos y propios del sector como de otros más genéricos y que pueden afectar a otros sectores económicos. Es decir, el turismo no sería un fenómeno «esencialmente» diferente de otras actividades económicas, que pueda considerarse como intrínsecamente positivo o negativo para el desarrollo socio-económico. En reali- 
dad, el turismo ha desempeñado en muchas sociedades turísticas un papel similar al que en otro tiempo y contexto desempeñó la revolución industrial. Así, el turismo ha implicado procesos de urbanización, elevación de la tasa de actividad, incremento de la interacción cotidiana de los sujetos sociales con otros individuos de clases/culturas/niveles adquisitivos. Pero todo eso sucedió también en las sociedades que experimentaron algún tipo de «revolución industrial».

Entrando ya en los factores que parecen condicionar la calidad del empleo turístico, en primer lugar tenemos el momento en que el desarrollo turístico tiene lugar y el contexto institucional de la sociedad en que se desenvuelve la actividad. Esto resulta, por lo demás, plenamente coherente con lo que se ha estudiado ampliamente para otros sectores de actividad. Siguiendo la línea planteada por autores como Boyer y Freyssenet (2001) para la industria del automóvil, la forma que adopta la estructura tecnológico-organizativa de un sector económico es el resultado de un equilibrio social. Por tanto, el que un sector (el turístico) use mano de obra más o menos cualificada y/o remunerada no es consecuencia tanto de las características intrínsecas a la organización de la producción de ese sector como del equilibrio social existente en una sociedad. En definitiva, la variable independiente no sería tan sólo las características del sector productivo (el turismo), que determinaría la «calidad» del empleo y el marco institucional y las relaciones de poder entre distintos agentes sociales que se generarían. Sino que también estas relaciones entre los agentes sociales acabarían determinando la estructura organizativa de un sector y el marco institucional.

En segundo lugar, hay que afirmar que el factor que parece condicionar más que cualquier otro la "calidad» del empleo turístico en una determinada empresa, localidad o destino es la posición que ésta ocupa en la red internacional de elaboración de servicios turísticos. Esto también resulta coherente con lo que autores como Castillo (1989) o Castells (2000) han analizado para otros sectores económicos. En tercer lugar, parece que un factor que influye de manera decisiva en la estabilidad del empleo turístico (y así en su calidad) es la estabilidad de la demanda. Lo cual, una vez más, no consiste más que en la aplicación de las ideas de Piore y Sabel (1989) al sector, que frecuentemente ha sido sometido a análisis "esencialistas" que se resistían a aplicar al mismo los conocimientos consolidados en otros sectores económicos. Por último, y es esto lo que quizá constituye la principal aportación de esta investigación, parece existir relación entre el origen geográfico del capital que pone en marcha la actividad turística y el de quienes acaban empleados en la misma. Esto entronca directamente con las teorías del desarrollo aplicadas al turismo. La actividad turística es vista frecuentemente, aún hoy, en términos maniqueos como algo tremendamente positivo para las comunidades en que se asienta (el turismo como pasaporte para el desarrollo) o bien como algo tremendamente negativo (el turismo como una nueva forma de colonialismo). Pues bien, creemos que el estudio del caso de Maspalomas es especialmente indicado para ilustrar esta polémica. La idea de que la población local conseguirá empleos en el turis- 
mo sólo si anteriormente se ha implicado en la puesta en marcha de la actividad constituye un punto intermedio entre las dos posturas anteriores. Esto es, las comunidades afectadas por él pueden esperar que el turismo, efectivamente, promueva el desarrollo socio-económico. Pero no como una especie de "pasaporte para el desarrollo", es decir, como algo que se recibe sin mayor esfuerzo de agentes externos a una comunidad. Si las comunidades afectadas por el desarrollo turístico no son capaces de gestionarlo de una manera adecuada podrán ver como éste, efectivamente, se convierte en una forma de neocolonialismo, en el que las transferencias de riqueza y los empleos que genera una comunidad acaban beneficiando a agentes externos a la misma. Y efectivamente, las comunidades locales recibirán los perjuicios (en forma de degradación ambiental, saturación, etc.) de una actividad de la que no reciben los beneficios (en forma, en muchos casos, de simples beneficios empresariales).

\section{Agradecimientos}

La investigación que aquí se ha presentado se basa en la tesis doctoral «Formas de desarrollo turístico, redes y situación de empleo. El caso de Maspalomas (Gran Canaria)», presentada por el autor de la comunicación en julio de 2003 en el Departamento de Sociología de la Universitat Autònoma de Barcelona. Dicha tesis fue posible gracias a la ayuda de muchas personas e instituciones. En primer lugar, la Dirección General de Universidades del Gobierno de Canarias y el Ârea de Universidad del Cabildo de Gran Canaria, que, con sus becas, hicieron posible la investigación. También la Fundación César Manrique de Lanzarote, que, al otorgarme la beca sobre Turismo y Territorio, me permitió estudiar los procesos de planeamiento urbano en el sur de Gran Canaria. Quiero expresar mi agradecimiento también hacia el Departamento de Sociología de la Universitat Autònoma de Barcelona, al cual debo mi formación intelectual y, especialmente, a mi director de tesis, Antonio Martín Artiles. Las compañeras y compañeros del Departamento de Sociología de la Universidad de La Laguna, aunque me acogieron una vez ya terminada la tesis, me han permitido continuar pensando en estas ideas. En especial quiero manifestar mi gratitud hacia Rosa Marrero, que me acompañó intelectualmente durante gran parte del proceso de elaboración de la tesis.

\section{Bibliografía}

BAYÓN, F; GARCía, I. (1997). Gestión de recursos humanos. Manual para técnicos en empresas turisticas. Madrid: Síntesis.

Benítez Rochel, J.; Robles TegeiRo, L. (1992). «Segmentación del mercado de trabajo turístico». Estudios Turisticos 115: 11-21.

BOYER, R; FREYSSENET, M. (2001). «El mundo que cambió la máquina. Un nuevo esquema de análisis de la industria del automóvil». Sociología del Trabajo, nueva época, 41, invierno 2000-2001: 3-45. 
Brunet Icart, A.; Belzunegui Eraso, A. (2003). «Sociología del Trabajo Turístico». En Rubio Gil, A. (2003) (coord.). Sociología del Turismo. Barcelona: Ariel Turismo.

CASTELLS, M. $\left(2000^{2}\right)$. «La empresa red: cultura, instituciones y organizaciones de la economía informacional». La era de la información. Vol. 1: La sociedad red. Madrid: Alianza Editorial.

CASTILlO, J.J. (1989). «La división del trabajo entre empresas». Sociología del Trabajo 5.

DíAZ, J.A.; FruTOS, A. (2003). "La dimensión socioestructural del turismo». En RUBIO GiL, A. (2003) (coord.). Sociología del Turismo. Barcelona: Ariel Turismo.

EsPino Rodríguez, T.F.; PADRÓn RoBAINA, V. (2004a). «La externalización hotelera bajo la visión de la empresa basada en los recursos». Annals of Tourism Research (en Español), vol. 6, n. ${ }^{\circ}$ 1: 175-198.

- (2004b). "Outsourcing and Its Impact on Operational Objectives and Performance: A Study of Hotels in the Canary Islands». International Journal of Hospitality Management, vol. 23: 287-306.

GaVIRIA, M. et al. (1978). España a go-go: Turismo chárter y neocolonialismo del espacio. Madrid: Turner.

Gobierno de CANARIAS (2003a). Estadisticas de turismo receptivo. Consejería de Turismo y Transportes, Viceconsejería de Turismo, Dirección General Ordenación e Infraestructura Turística, Servicio de Ordenación Turística. [En internet: http://www.gobiernodecanarias.org/turismoldgoitlestadisticas/mestadis.html]

- (2003b). Plazas turísticas. Consejería de Turismo, Viceconsejería de Turismo, Dirección General de Ordenación y Promoción Turística, Servicio de Ordenación Turística. [En internet: http://www.gobiernodecanarias.org/turismo/dgoitlestadisti cas/mestadis.html]

HARRISON, B. (1997). La empresa que viene. La evolución del poder empresarial en la era de la flexibilidad. Barcelona: Paidós.

INE (2001). Análisis de la ocupación de los alojamientos turísticos de España. Año 2000. Madrid: Instituto Nacional de Estadística. [Disponible parcialmente en internet: www.ine.es]

- (2002a). Encuesta de Ocupación en Alojamientos Turísticos. Establecimientos Hoteleros. Total 2002. Datos Provisionales. Madrid: Instituto Nacional de Estadística. Notas de Prensa. [Disponible en Internet: www.ine.es]

- (2002b). Encuesta de Ocupación en Alojamientos Turísticos. Apartamentos Turísticos. Año 2002. Madrid: Instituto Nacional de Estadística. Notas de Prensa. [Disponible en Internet: www.ine.es]

- (2002c). Encuesta de Ocupación en Alojamientos Turísticos. Acampamientos Turísticos. Año 2002. Madrid: Instituto Nacional de Estadística. Notas de Prensa. [Disponible en Internet: www.ine.es]

- (2002d). Encuesta de Ocupación en Alojamientos Turísticos. Alojamientos de Turismo Rural. Año 2002. Madrid: Instituto Nacional de Estadística. Notas de Prensa. [Disponible en Internet: www.ine.es]

Jurdao ArRones, F. (1992). Los mitos del turismo. Madrid: Endimión.

MARrero RodríGUEZ, J.R. (1996). "Semejanzas y diferencias en la producción de bienes y servicios. Una reflexión sociológica a partir de la reestructuración de la actividad turística». Sociología del Trabajo 26: 63-80.

- (2000). "Estructura social y reclutamiento de la mano de obra». Sociología del Trabajo 38.

- (2003). La estructura y dinámica de los mercados de trabajo. El caso del sector turístico canario. Las Palmas de Gran Canaria: Ediciones del Cabildo de Gran Canaria. 
Mathieson, A.; Wall, G. (1990). Turismo: repercusiones económicas, físicas y sociales. México: Trillas [Ed. original en inglés de 1986.]

Mazón Martínez, T.; Aledo Tur, A. (2004). Los límites del turismo residencial. El caso de Torrevieja. Comunicación presentada en el VIII Congreso Español de Sociología, Grupo de Trabajo 09: Turismo, Ocio y Deporte. Federación Española de Sociología (FES). [Edición en CD-ROM.]

Melián González, A.; García Falcón, J.M. (2003). "Competitive Potential of Tourism in Destinations». Annals of Tourism Research, vol. 30, n. ${ }^{\circ} 3:$ 720-740.

MingIONE, E. (1994). Las sociedades fragmentadas. Una sociología de la vida económica más allá del paradigma del mercado. Madrid: Ministerio de Trabajo y Seguridad Social.

Osterman, P. (1988). Los mercados internos de trabajo. Madrid: Ministerio de Trabajo y Seguridad Social.

REQUena SAntos, F. (1991). Redes sociales y mercado de trabajo. Madrid: Centro de Investigaciones Sociológicas (CIS).

Rubio Gil, A. (2003). "Turismo, sociedad y desarrollo». En Rubio GiL, A. (2003) (coord.). Sociología del Turismo. Barcelona: Ariel Turismo.

SANCHO, A. (1998). "El turismo como actividad económica». Introducción al Turismo. Madrid: Organización Mundial del Turismo (OMT).

SANTANA SÁNCHEZ, Y. (2002). "Informe de coyuntura del mercado turístico alemán. Invierno 01/02». Proyecto Internacionalización de la oferta turística de Gran Canaria. Las Palmas de Gran Canaria: Patronato de Turismo de Gran Canaria, Federación de Empresarios de Hostelería y Turismo, Sociedad Promoción Económica de Gran Canaria, Turespaña.

Santana Santana, M.C. (1993). La producción del espacio turístico en Canarias. Las Palmas de Gran Canaria: Ediciones del Cabildo Insular de Gran Canaria, Geografía.

SANTANA TAlaVERA, A. (1997). «Turismo y desarrollo: revisión de los impactos generados». Antropología y turismo: ;nuevas hordas viejas culturas?

SAnTANa TurÉgAno, M.A. (2003). Formas de desarrollo turístico, redes y situación de empleo. El caso de Maspalomas (Gran Canaria). [Tesis doctoral, Universitat Autònoma de Barcelona, disponible en http://www.tdx.cesca.es/TDX-0123104-173733/]

SAYER, A.; WALKER, R. (1994). "Más allá del fordismo y de la flexibilidad». La nueva economía social. Madrid: Ministerio de Trabajo y Seguridad Social.

SinClair, M.T. (1991). "The economics of tourism». En COOPER, C. (ed.) (1991). Progress in tourism, recreation and hospitality management. Londres: Bellhaven Press.

SCHLUETER PARrilla, A. (2002). "Informe de coyuntura del mercado británico. Invierno 01/02». Proyecto Internacionalización de la oferta turística de Gran Canaria. Las Palmas de Gran Canaria: Patronato de Turismo de Gran Canaria, Federación de Empresarios de Hostelería y Turismo, Sociedad Promoción Económica de Gran Canaria, Turespaña.

Turner, L.; ASH, J. (1991). La hora dorada. Madrid: Endimión. [La versión original inglesa es de 1976.]

VAllejO, M.A. (2002). Informe de coyuntura del mercado turístico danés. Invierno 01/02. Proyecto Internacionalización de la oferta turística de Gran Canaria. Las Palmas de Gran Canaria: Patronato de Turismo de Gran Canaria, Federación de Empresarios de Hostelería y Turismo, Sociedad Promoción Económica de Gran Canaria, Turespaña.

Wanhill, S. (2000). Small and medium tourism enterprises. Annals of Tourism Reseach, vol. 27 , n. ${ }^{\circ}$ 1: 132-147. 